\title{
Lingual Schwannoma: A Diagnostic to Remember! A Case Report with Review of Literature
}

\author{
Zahra Sayad $^{1 *}$, Najwa Belhaj ${ }^{2}$, Ihssane Allouch ${ }^{2}$, S. Nitassi ${ }^{2}$, R. Bencheikh ${ }^{2}$, A. Oujilal ${ }^{2}$, M.A. Benbouzid ${ }^{2}$, Benazzou S $^{1}$,
} Essakalli $\mathrm{L}^{2}$, Boulaadas $\mathrm{M}^{1}$

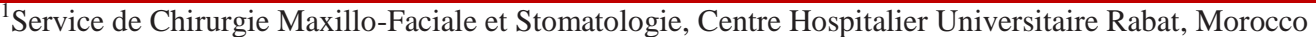

${ }^{2}$ Service ORL-CCF, Centre Hospitalier Universitaire Rabat, Morocco

DOI: $10.36347 /$ sjams.2021.v09i03.003

| Received: 16.02.2021 | Accepted: 27.02.2021 | Published: 03.03.2021

*Corresponding author: Zahra Sayad

\section{Abstract}

Case Report

Lingual schwannoma is a benign, slowly growing tumor of Schwann cells of the nerve sheath. $25 \%$ of schwannomas are found in the cervicofacial sphere, but only $1-12 \%$ in the oral cavity. A tongue is the structure most affected. We report a case of schwannoma of the oral cavity, discuss the different possible differential diagnoses, and specify the interest of the histopathologic exam finished through an immunohistochemical test. Schwannomas clinically represent swelling along the peripheral nerves. Only surgery with histological examination and immunohistochemistry makes the diagnosis possible and can differentiate schwannomas from neurofibromas and other differential diagnoses. Malignant changes in schwannomas are extremely rare.

Keywords: Tongue, Schwannoma, diagnostic.

Copyright $(\odot) 2021$ The Author(s): This is an open-access article distributed under the terms of the Creative Commons Attribution 4.0 International License (CC BY-NC 4.0) which permits unrestricted use, distribution, and reproduction in any medium for non-commercial use provided the original author and source are credited.

\section{INTRODUCTION}

Schwannoma, also called neuroma, represents a slowly growing benign tumor of Schwann cells of neuroectodermal origin, often developing at the expense of the peripheral motor and sensory nervous system [1].

Around $25-40 \%$ of schwannomas are in the head and neck region, but only $1-12 \%$ affect the oral area, most frequently the tongue and mouth floor. Despite its rarity, the intraoral schwannomas must be included in the differential diagnosis of tongue mass [1, 2].

We report a case of the oral cavity schwannoma; we discuss the clinical and pathologic characteristics, the different possible differential diagnoses, and specify the interest of the histopathological examination supplemented by an examination immunohistochemical, the only way to make a positive diagnosis of benign schwannoma.

\section{Case Report}

A 56-year-old female, also without significant personal or family medical history. He presents a submucosal swelling on the left border of the tongue, without lingual motility disorder, pain, or hypoesthesia (Fig. 1).

The clinical examination revealed an encapsulated nodular mass $(1,7 \times 1,5 \mathrm{~cm}$ in size $)$, firm, mobile, without any mucosal ulceration or lymphadenopathy.

A Magnetic resonance imaging was performed to characterize the lesion, revealing the presence of a homogeneous nodule in the left tongue, well circumscribed; isointense to muscle on T1- weighted images and hyperintense on T2-weighted images (Fig. 2).

The treatment was total excision of the mass under local anesthesia (Figure 2). Gross examination revealed an encapsulated yellow nodule. The histopathological and immunohistochemical examination confirmed the diagnosis of schwannoma. 


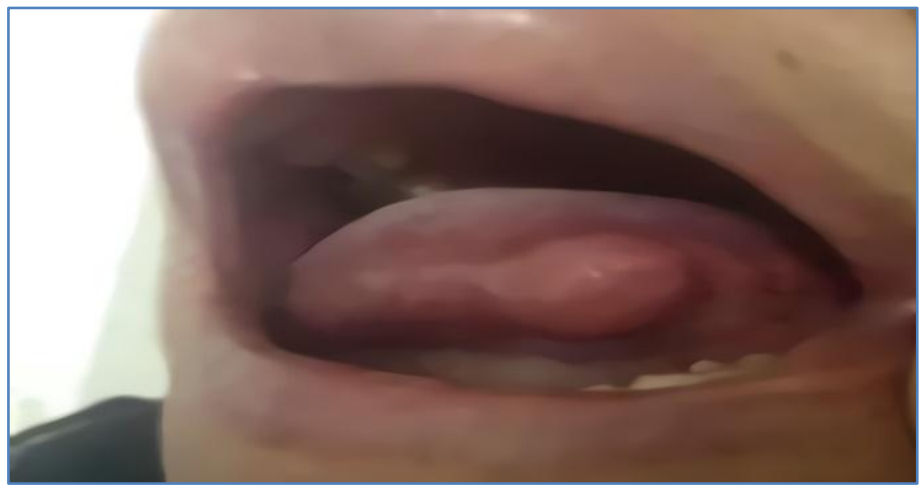

Fig-1: Preoperative intraoral photograph revealed a mass in the left tongue base, covered by normal oral mucosa

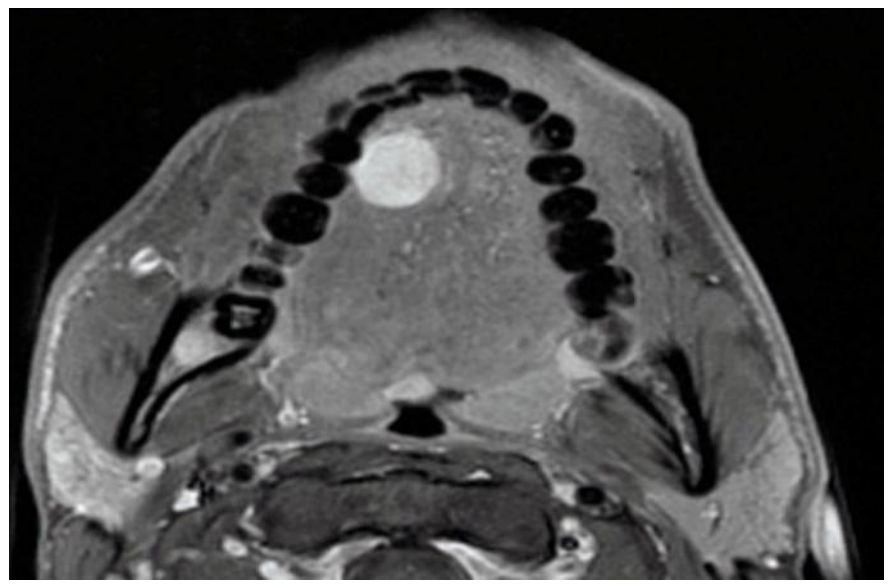

Fig-2: MR imaging with gadolinium injection demonstrated a homogeneous nodule in the left tongue, well-circumscribed

\section{DISCUSSION}

Schwannoma is a benign, slow-growing tumor that arises from Schwann cells, of the nerve sheath. Approximately $25-45 \%$ of all schwannomas are developing in the cervicofacial region; only $1-12 \%$ of them concern the oral cavity; they represent 1 to $9 \%$ of all stomatological tumors [2, 3].

In the oral cavity, the tongue is most affected, followed by the palate, mouth floor, buccal mucosa, the gingiva, the lips, and the vestibular mucosa $[4,5]$.

They can occur at any age, but especially between 20 and 40 years (67\% of cases) and there is no predominance of sex or race [6].

Typically, schwannoma affect frequently the anterior third of the tongue $(66 \%$ vs $34 \%$ in the posterior two thirds). The lesion is usually slowgrowing, single. Multiple schwannomas (schwannomatosis) can be observed in neurofibromatosis type II, which is characterized, among other things, by acoustic schwannoma, bilateral or not. Benign schwannoma poses the problem of diagnosis with other nerve tumors, especially with neuromas, consisting of an overgrowth of axons and Schwann cells, most often induced by local trauma; but also, with Abrikossoff tumor, gliomas, neurothekeoma, extracranial meningiomas, chondromas, melanotic neuroectodermal tumors. In addition to nerve tumors, the differential diagnosis arises with lipomas, leiomyomas, hemangiomas, lymphangiomas and benign or malignant tumors of the salivary glands $[7,8]$.

Clinically, schwannomas are most often asymptomatic, solitary, slow growing, but they can be accompanied by pain, mucosal ulceration, or paresthesia in $50 \%$ of cases. For lingual localization, the examination shows firm and regular swelling, mucous ulcerations are extremely rare [9].

The CT scan shows a heterogeneous or homogeneous mass, respecting the soft tissues, with heterogeneous enhancement. However, MRI is the imaging modality of choice for lingual schwannomas. It is superior compared to computed tomography (CT), allows a more precise localization of the mass in relation to other structures, as well as a more accurate measurement of tumor size. The typical features on MRI are a well-circumscribed small nodule, homogeneously isointense versus muscle on $\mathrm{T} 1$ weighted images (Fig. 1A) and homogeneously hyperintense on T2-weighted images (Fig. 1B), showing homogeneous enhancement after contrast administration (Fig. 2 C, D) [5,10].

Schwannomas are usually treated by surgical complete excision without a safety margin if it is well encapsulated [5]. 
Zahra Sayad et al; Sch J App Med Sci, Mar, 2021; 9(3): 309-311

Histologically, all schwannomas are encapsulated. The tumor is composed of two cell populations, hypercellular spindle cell areas with nuclear palisading (Antoni type A), and Antoni type B, which is also composed of elongated Schwann cells, but cells are small round arranged in a less dense myxoid manner and are more disorganized than Antoni type A (Fig. 6). The appearance of cells is an important argument for the diagnosis. Spindle-shaped cells have irregular outlines with curved, wavy, or comma-shaped asymmetric nuclei. The cytoplasm is poorly colored, with barely visible limits. Schwannomas are characterized by strong and diffuse immunoreactivity for S-100 protein (Fig. 2D), which is the clue for the diagnosis $[11,12]$.

Enoz et al. reported a malignant transformation rate for head and neck schwannoma of $8-10 \%$. Only one involved the tongue was reported [13, 14].

Despite this risk of malignant transformation, benign schwannomas have a good prognosis if surgical excision is complete, recurrences are exceptional. In contrast, malignant schwannoma is a tumor with a poor prognosis with an overall survival of 20 to $25 \%$ in case of Recklinghausen's disease and $50 \%$ in case of isolated tumor. The poor prognosis of Recklinghausen's disease is related to the location of the tumors (more often in the trunk or proximal), the size and higher grade, and the fact that some patients develop several sarcomas simultaneously. Local recurrence is frequent, and metastases (lung, liver, skin, and bone) usually appear within two years of diagnosis [15].

\section{CONCLUSION}

Lingual schwannoma is a rare tumor; however, it should be considered in the differential diagnosis list in front of well-circumscribed small nodule of the tongue. The histopathological and immunohistochemical analysis allows the diagnosis with certainty. The treatment is only surgical and consists of a transoral complete resection. They are rarely recurrences or malignant transformation. Future research must define the etiologies, factors of malignant transformation and recurrence to better highlight this tumor.

\section{REFERENCES}

1. Cohen M, Wang MB. Schwannoma of the tongue: two case reports and review of the literature.
European Archives of Oto-Rhino-Laryngology. 2009 Nov;266(11):1823-9.

2. Weiss SW, Goldblum JR, Enzinger and Weiss's Soft Tissue Tumors, 4th edition, Mosby Inc., 2001: 1111-1207.

3. Cinar F, Cinar S, Harman G. Schwannoma of the tip of the tongue in a child. Plast Reconstruct Surg, 2004; 114: 1657-8.

4. Tsushima F, Sawai T, Kayamori K, Okada N, Omura K. Schwannoma in the floor of the mouth: a case report and clinicopathological studies of 10 cases in the oral region. J Oral Maxillofac Surg Med Pathol. 2012; 24:175-179

5. Eun-Young Lee, Jae-Jin Kim, Hyun Seok and JaYoun Lee. Schwannoma of the tongue: a case report with review of literature. Maxillofacial Plastic and Reconstructive Surgery. 2017; 39:17

6. Bhola N, Jadhav A, Borle R, Khemka G, Bhutekar U, Kumar S. Schwannoma of the tongue in a paediatric patient: a case report and 20-year review. Case Rep Dent. 2014; 2014:780762.

7. Avcu N, Kansu O, Uysal S, Kansu H. Cranioorbitaltemporal neurofibromatosis with cerebral hemiatrophy presenting as an intraoral mass: a case report. J Calif Dent Assoc. 2009; 37: 119-21. 10

8. Zachariades N, Mezitis M, Vairaktaris E, Triantafyllou D, Skoura-Kafoussia C, KonsolakiAgouridaki E, Hadjiolou E, Papavassiliou D. Benign neurogenic tumors of the oral cavity. Int $\mathrm{J}$ Oral Maxillofac Surg. 1987; 16: 70-6

9. I.Abreua, Diogo Roriz, Pedro Rodrigues b, Ângela Moreiraa, Cristina Marques a, Filipe Caseiro Alves. Schwannoma of the tongue-A common tumour in a rare location: A case report. European Journal of Radiology Open 4; 2017: 1-3

10. La'porte S, Juttla J, Lingam R. Imaging the floor of the mouth and the sublingual space. Radiographics. 2011; 31:1215-1230

11. Fisher C, Diagnostic Pathology: Soft Tissue Tumors, 2nd edition, Amirsys; 2011.

12. Lindberg MR. Diagnostic Pathology: Soft Tissue Tumors, 2nd edition, Amirsys; 2016.

13. Enoz M, Suoglu Y, Ilhan R. Lingual schwannoma. J Cancer Res Ther. 2006; 2:76-78

14. Moreno-García C, Pons-García M, GonzalezGarcía R, Monje-Gil F. Schwannoma of tongue. J Maxillofac Oral Surg. 2014; 13:217-221.

15. Lachere A, Kerrary S, Chaine A, Bouvier S, Rigolet A, Bertolus C. Schwannoma of the tongue: case report and literature review. Médecine buccale chirurgie buccale. $2009 ; 15(4)$. 